\title{
Life Cycle of Dermacentor everestianus Hirst, 1926 (Acari: Ixodidae) under Laboratory Conditions
}

\author{
Shang Jin ${ }^{1, \dagger}$, Tianhong Wang ${ }^{1, \dagger}$, Tuo Li', Ming Liu', Qingying Jia', Xiaolong Yang ${ }^{1}$, Hui Wang ${ }^{1}$, Zhijun Yu ${ }^{1,2, *}$, \\ Jingze Liu'** \\ ${ }^{1}$ Key Laboratory of Animal Physiology, Biochemistry and Molecular Biology of Hebei Province, College of Life Sciences, Hebei Normal University, \\ Shijiazhuang 050024, China; 'Institute of Biochemistry, Carleton University, 1125 Colonel By Drive Ottawa, Ontario K1S 5B6, Canada
}

\begin{abstract}
This study investigated the development characteristics of Dermacentor everestianus under laboratory conditions. The time taken for $D$. everestianus to complete the whole life cycle was 110.2 days on average, and the average developmental durations of larvae and nymphs were 17.1 days and 29.5 days, respectively. The summation of the prefeeding, feeding, and preoviposition periods of females was 17.8 days, and the oviposition and egg incubation lasted for 18.1 days and 27.7 days, respectively. A highly positive correlation was observed between the weight of engorged female and the number of egg mass laid $(r=0.947)$. The reproductive efficiency index and the reproductive fitness index were 7.1 and 6.1 , respectively.
\end{abstract}

Key words: Dermacentor everestianus, ixodid tick, life cycle, laboratory, development

\section{INTRODUCTION}

Ticks are globally distributed bloodsucking ectoparasites, which are notorious as vectors in maintaining enzootic cycles of numerous pathogens [1]. Among the approximately 900 tick species worldwide [2], the tick Dermacentor everestianus Hirst, 1926 is mainly distributed in Northwestern China and Nepal [3], and recognized as an important vector of Anaplasma ovis, Francisella tularensis, and Rickettsia raoultii-like bacteria in Qinghai-Tibet Plateau of China, including Qinghai, Tibet, and Gansu province [4]. Additionally, this tick species even occurs above 4,000 meters in altitude in Tibet Plateau [5], where is featured by extremely hostile environments, including poor oxygen, drought conditions, and low temperatures [6].

As a 3-host tick, the immature D. everestianus usually attacks lagomorphs and rodents, whereas the adults mainly parasitize on hares, domestic sheep, and yaks, which cause great losses in livestock production [5]. Though the tick D. everestianus was regarded a junior synonym of $D$. abaensis and $D$. birulai [3], detailed knowledge on their biology and life cycle has not been

- Received 15 June 2016, revised 12 February 2017, accepted 6 March 2017.

*Corresponding author (yzj116@163.com; liujingze@hebtu.edu.cn)

${ }^{\dagger}$ These authors contributed equally to this study.

(c) 2017, Korean Society for Parasitology and Tropical Medicine

This is an Open Access article distributed under the terms of the Creative Commons Attribution Non-Commercial License (http://creativecommons.org/licenses/by-nc/4.0) which permits unrestricted non-commercial use, distribution, and reproduction in any medium, provided the original work is properly cited. thoroughly studied. Therefore, this paper investigated the development characteristics of $D$. everestianus under laboratory conditions, which will be helpful for further exploration of its ecological adaptation to the hostile environments in QinghaiTibet Plateau, China.

\section{MATERIALS AND METHODS}

\section{Collection and rearing of the ticks}

D. everestianus adult ticks were collected by flag-dragging in the field in Damxung County $\left(90^{\circ} 45^{\prime}\right.$ to $91^{\circ} 31^{\prime} \mathrm{E}, 29^{\circ} 31^{\prime}$ to $31^{\circ} 04^{\prime} \mathrm{N}, 4353 \mathrm{~m}$ in altitude), north Lhasa City, Tibet Autonomous Region, China. Ticks were placed into cloth bags attached on ears of domestic rabbits, and were checked daily for feeding or engorgement. During non-feeding periods, they were incubated in cotton-plugged glass tubes in laboratory incubator, i.e., $22 \pm 1^{\circ} \mathrm{C}, 75 \pm 5 \%$ relative humidity $(\mathrm{RH})$, and a $16 \mathrm{hr}$ light and $8 \mathrm{hr}$ darkness photoperiod. The rabbits were maintained at $20-25^{\circ} \mathrm{C}$ with $50 \% \mathrm{RH}$ and exposed to natural daylight cycles, and each rabbit was used only for a single infestation.

\footnotetext{
Biology of the immature and adult $D$. everestianus

To evaluate the prefeeding period (no. of days from emergence to attachment) of immature and adult $D$. everestianus, 100 newly emerged larvae and nymphs and 50 newly molted females were put on hosts, and checked daily for attachment.
} 
Three weeks after emergence, 300 immature ticks and 50 females and males were weighed and fed on rabbits, and the feeding periods (no. of days from attachment to detachment) were determined. After engorgement, immature ticks were collected, weighed, and then placed into separate tubes for molting in a laboratory incubator. Premolting periods of the larvae and nymphs were recorded from their detachment to ecdysis according to Labruna et al. [7].

\section{Biology of engorged females}

After engorgement, detached females were immediately collected and weighed individually, then they were put into separate tubes for oviposition in the laboratory incubator. The preoviposition periods (no. of days from detachment to the beginning of oviposition) and oviposition periods (no. of days from the beginning to the end of oviposition) of females were recorded. Once oviposition started, the daily deposited eggs were collected, weighed, and placed into separate glass tubes. A thousand eggs were used for observing the incubation period (no. of days from oviposition to the first larva hatchment), and percent of hatchment was calculated. Additionally, the reproductive efficiency index (REI) (amount of eggs/weight of engorged female) [8] and the reproductive fitness index (RFI) (amount of eggs incubated to larvae/weight of engorged female) [9] were also determined as described by Chen et al. [10].

\section{RESULTS}

\section{Life cycle of $D$. everestianus}

Under laboratory conditions, a mean of 110.2 days (range

Table 1. The duration of various developmental stages of Dermacentor everestianus under laboratory conditions

\begin{tabular}{llrrr}
\hline \multirow{2}{*}{$\begin{array}{l}\text { Developmental } \\
\text { stages }\end{array}$} & \multicolumn{1}{c}{ Period } & No. & \multicolumn{2}{c}{ Duration (day) } \\
\cline { 5 - 5 } & & & Range & Mean \pm SEM \\
\hline Egg & Incubation & 1,000 & $24-31$ & $27.7 \pm 1.9$ \\
Larva & Prefeeding & 100 & $2-3$ & $2.5 \pm 0.5$ \\
& Feeding & 100 & $1-3$ & $2.4 \pm 0.6$ \\
& Premoulting & 300 & $11-13$ & $12.2 \pm 0.7$ \\
Nymph & Prefeeding & 100 & $2-4$ & $3.2 \pm 0.7$ \\
& Feeding & 100 & $3-5$ & $4.1 \pm 0.7$ \\
& Premoulting & 300 & $20-25$ & $22.2 \pm 1.6$ \\
Female & Prefeeding & 50 & $4-7$ & $5.3 \pm 0.9$ \\
& Feeding & 50 & $3-8$ & $5.7 \pm 1.2$ \\
& Preoviposition & 20 & $5-10$ & $6.8 \pm 1.2$ \\
& Oviposition & 20 & $12-27$ & $18.1 \pm 3.6$ \\
\hline Life cycle & & 20 & $87-136$ & $110.2 \pm 13.6$ \\
\hline
\end{tabular}

87-136 days) were required for the tick D. everestianus to complete the whole life cycle from unfed adults to next generation adults. The average developmental durations of larvae and nymphs were 17.1 days (range 14-19 days) and 29.5 days (range 25-34 dyas), respectively. The summation of the prefeeding, feeding, and preovipositon periods of females was 17.8 days, and the oviposition and egg incubation lasted for 18.1 days (range 12-27 dyas) and 27.7 days (range 24-31 days), respectively. The durations of the various developmental stages are shown in Table 1.

\section{Feeding biology and changes of body weight}

After ecdysis, the larvae, nymphs, and adults required an average of 2.5 days (range 2-3 days), 3.2 days (range 2-4 days), and 5.3 days (range 4-7 days) to acquire the ability to attach on hosts for feeding, respectively. When feeding began, it took an average of 2.4 days and 4.1 days for larvae and nymphs to engorge. The premolting periods of larvae and nymphs averaged 12.2 days (range 11-13 days) and 22.2 days (range 20-25 days), respectively. Copulation is necessary for rapid engorgement of females, and after engorgement, the average weights of females increased by about 41.2 folds, whereas no obvious difference was observed on weight changes of males (1.2-fold). For larvae and nymphs, the weight ratio of engorged to unfed was 10.2 and 27.5 , respectively. The average body weights of the larvae, nymphs, and adults before and after feeding are listed in Table 2.

Table 2. Changes of the body weights of larvae, nymphs, and adults of Dermacentor everestianus before and after feeding

\begin{tabular}{lrccc}
\hline $\begin{array}{l}\text { Developmen- } \\
\text { tal stages }\end{array}$ & No. & $\begin{array}{c}\text { Unfed }(\mathrm{mg}) \\
\text { (Mean } \pm \text { SEM) }\end{array}$ & $\begin{array}{c}\text { Engorged }(\mathrm{mg}) \\
\text { (Mean } \pm \text { SEM) }\end{array}$ & $\begin{array}{c}\text { Weight ratio (en- } \\
\text { gorged/unfed) }\end{array}$ \\
\hline Larva & 100 & $0.058 \pm 0.00$ & $0.594 \pm 0.00$ & 10.2 \\
Nymph & 100 & $0.46 \pm 0.04$ & $12.65 \pm 3.30$ & 27.5 \\
Female (\&) & 50 & $7.15 \pm 0.74$ & $294.80 \pm 63.85$ & 41.2 \\
Male (ठ゚) & 50 & $6.28 \pm 1.07$ & $7.72 \pm 0.48$ & 1.2 \\
\hline
\end{tabular}

Table 3. The characteristics of oviposition of Dermacentor everestianus under laboratory conditions

\begin{tabular}{lrcc}
\hline Parameters & No. & Range & Mean \pm SEM \\
\hline $\begin{array}{l}\text { Weight of engorged female } \\
\text { (mg/ } \text { ( ) }\end{array}$ & 50 & $204.6-444.1$ & $294.8 \pm 63.9$ \\
Egg mass laid (No./\%) & 20 & $1,364-2,951$ & $2,126.0 \pm 623.9$ \\
Hatchment rate (\%) & 1,000 & $78.4-94.6$ & $85.9 \pm 4.5$ \\
REI & 20 & $6.32-8.21$ & $7.1 \pm 0.12$ \\
RFI & 20 & $5.26-7.26$ & $6.1 \pm 0.13$ \\
\hline
\end{tabular}




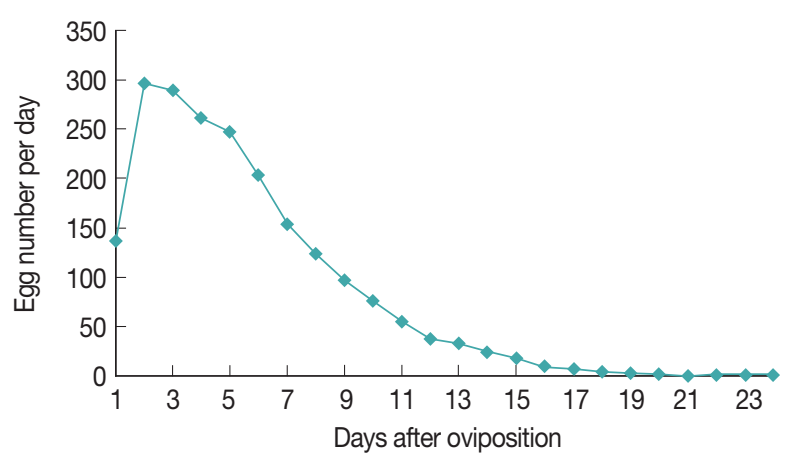

Fig. 1. Mean daily oviposition of engorged females of Dermacentor everestianus (based on 20 females) under laboratory conditions.

\section{Oviposition}

The egg mass laid by the tick D. everestianus ranged from 1,364 to 2,951 per female, and percent of hatchment reached $85.9 \%$. The REI and RFI was 7.1 and 6.1, respectively (Table 3). The egg amount was relatively low at the onset of oviposition, and peaked on the second day, thereafter the egg number gradually declined. The daily oviposition of $D$. everestianus is presented in Fig. 1. Linear regression analysis revealed a highly positive correlation between the weight of the engorged female and the number of egg mass laid ( $r=0.947)$ (Fig. 2).

\section{DISCUSSION}

The tick D. everestianus is endemic in Qinghai-Tibet Plateau of China, and can transmit diseases between wild animals and livestock [5]. However, the biology and development characteristics of this tick species has not been extensively studied yet, which has hampered the understanding of its vector potential and ecological adaptation to hostile environment. Therefore, the current study investigated the biological characteristics of all developmental stages of $D$. everestianus, using rabbits as the host under laboratory conditions $\left(22 \pm 1^{\circ} \mathrm{C}, 75 \pm 5 \% \mathrm{RH}\right.$, and a $16 \mathrm{hr}$ light and $8 \mathrm{hr}$ darkness photoperiod).

The duration of the life cycle of $D$. everestianus averaged 110.2 days (ranged 87-136 days) under laboratory conditions, which was shorter than that of D. variabilis (176-191 days) and D. occidentalis (180-195 days) incubated at $22-24^{\circ} \mathrm{C}$ and $90 \% \mathrm{RH}$ [11], though they both used rabbits as hosts. When compared to the life cycle of $D$. silvarum (87.5 days in average, range 74102 days) under $27 \pm 1^{\circ} \mathrm{C}$ and $70 \% \mathrm{RH}[12]$, the tick D. everestianus required a longer duration. Hence, the differences of the development duration may still attribute to the complex interplay of ambient temperature and relative humidity $[13,14]$.

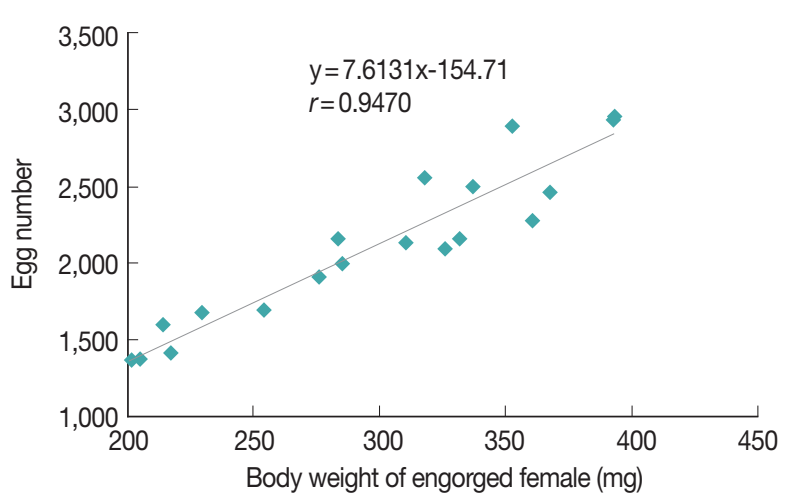

Fig. 2. Relationship between the weight of engorged females of Dermacentor everestianus and number of eggs laid (based on 20 females) under laboratory conditions.

The body weights of engorged females (294.8 mg on average, range $204.6-444.1 \mathrm{mg}$ ) and nymphal (12.7 mg on average, range 3.4-19.8 mg) D. everestianus were much lower than that of D. silvarum (461.4 $\mathrm{mg}$ in female, $64.7 \mathrm{mg}$ in nymph). Before and after feeding, the weight ratio of female D. everestianus from unfed to engorgement was approximately 41.2-fold, which was lower than 76.1 folds in D. silvarum, whereas the 27.5 folds weight increase in nymphs were much higher than that observed in D. silvarum (11.3 folds), and no difference was observed in larval weight changes between these 2 species [12].

Linear regression analysis revealed a highly positive correlation between the weight of the engorged female D. everestianus and the number of the egg mass laid $(r=0.947)$. The amount of eggs laid was low at the onset of oviposition, and reached the peak on the second day; thereafter, the egg amount was gradually decreased until the end of oviposition. The unimodel oviposition pattern was also observed in other tick species, including D. silvarum, Haemaphysalis doenitz [15], and Hyalomma asiaticum [16]. The egg incubation required an average of 27.7 days, which was much longer than that observed in $D$. silvarum (15.3 days on average, range 13-16 days) [12], but shorter than 32.1 days (range 25-40 days) observed in Haemaphysalis tibetensis under field conditions [16]. Premolting period of nymphs required 22.2 days under laboratory conditions, which was longer than 14.6 days (range 13-15 days) in D. silvarum [12], but much shorter than 52.7 days (range 41-55 days) in H. tibetensis which showed overlapping distribution [17].

Overall, the laboratory colony of $D$. everestianus was established, which paved the way for further exploration of its vector potential and allowed us to study its ecological adaptation 
to hostile environments in Qinghai-Tibet Plateau, China.

\section{ACKNOWLEDGMENTS}

This work was supported by National Natural Science Foundation of China (nos. 31272372, 31400342), the Specialized Research Fund for the Doctoral Program of Higher Education of China (no. 20131303130001), the Natural Science Foundation of Hebei province (no. C2015205124), and Natural Science Research Programs of the Educational Department of Hebei Province (no. BJ2016032). The visit of Zhijun Yu to the Carleton University was generously supported by China Scholarship Council and Hebei Normal University.

\section{CONFLICT OF INTEREST}

We declare that we have no conflict of interest related to this work.

\section{REFERENCES}

1. Sonenshine DE, Roe RM. Biology of Ticks. 2nd ed. New York, USA. Oxford. 2013.

2. Dantas-Torres F, Chomel BB, Otranto D. Ticks and tick-borne diseases: a One Health perspective. Trends Parasitol 2012; 28: 437-446.

3. Apanaskevich DA, Duan W, Apanaskevich MA, Filippova NA, Chen J. Redescription of Dermacentor everestianus Hirst (Acari: Ixodidae), a parasite of mammals in mountains of China and $\mathrm{Ne}$ pal with synonymization of $D$. abaensis Teng and $D$. birulai Olenev. J Parasitol 2014; 100: 268-278.

4. Yu ZJ, Wang H, Wang TH, Sun WY, Yang XL, Liu JZ. Tick-borne pathogens and the vector potential of ticks in China. Parasit Vectors $2015 ; 8: 24$

5. Teng KF, Jiang ZJ. Economic Insect Fauna of China. Fasc. 39, Acari: Ixodidae. Beijing, China. Science. 1991 (in Chinese).
6. Dai J, Wang Y, Zhang L, Tang YL, Luo XS, An HL, Fang CX. Hymenobacter tibetensis sp. nov., a UV-resistant bacterium isolated from Qinghai-Tibet plateau. Syst Appl Microbiol 2009; 32: 543548.

7. Labruna MB, Souza SL, Menezes AC, Horta MC, Pinter A, Gennari SM. Life-cycle and host specificity of Amblyomma tigrinum (Acari: Ixodidae) under laboratory conditions. Exp Appl Acarol 2002; 26: 115-125.

8. Drummond RO, Whetstone TM. Oviposition of the Gulf Coast tick. J Econ Entomol 1970; 63: 1547-1551.

9. Chilton NB. An index to assess the reproductive fitness of female ticks. Int J Parasitol 1992; 22: 109-111.

10. Chen Z, Li YQ, Liu ZJ, Yang JF, Yin H. The life cycle of Hyalomma rufipes (Acari: Ixodidae) under laboratory conditions. Exp Appl Acarol 2012; 56: 85-92.

11. Troughton DR, Levin ML. Life cycles of seven ixodid tick species (Acari: Ixodidae) under standardized laboratory conditions. J Med Entomol 2007; 44: 732-740.

12. Liu JZ, Liu ZN, Zhang Y, Yang XL, Gao ZH. Biology of Dermacentor silvarum (Acari: Ixodidae) under laboratory conditions. Exp Appl Acarol 2005; 36: 131-138.

13. Chilton NB, Andrews RH, Bull CM. Influence of temperature and relative humidity on the moulting success of Amblyomma limbatum and Aponomma hydrosauri (Acari: Ixodidae) larvae and nymphs. Int J Parasitol 2000; 30: 973-979.

14. Debárbora VN, Mangold AJ, Oscherov EB, Guglielmone AA, Nava S. Study of the life cycle of Amblyomma dubitatum (Acari: Ixodidae) based on field and laboratory data. Exp Appl Acarol 2014; 63: 93-105.

15. Chen XJ, Yu ZJ, Guo LD, Li LX, Meng H, Wang D, Liu RJ, Liu JZ. Life cycle of Haemaphysalis doenitzi (Acari: Ixodidae) under laboratory conditions and its phylogeny based on mitochondrial 16S rDNA. Exp Appl Acarol 2012; 56: 143-150.

16. Chen Z, Yu ZJ, Yang XL, Zheng HY, Liu JZ. The life cycle of Hyalomma asiaticum kozlovi Olenev, 1931 (Acari: Ixodidae) under laboratory conditions. Vet Parasitol 2009; 160: 134-137.

17. Liu M, Li T, Yu ZJ, Gao XH, Zuo CW, Wang RR, Li NX, Wang H, Liu JZ. Characterization of the life cycle of the tick Haemaphysalis tibetensis under field conditions in Qinghai-Tibet plateau. Exp Appl Acarol 2016; 69: 107-115. 